\title{
COOPETITION UNDER ALLIANCE? APPLYING AWARENESS-MOTIVATION-CAPABILITY COMPETITIVE DYNAMICS PERSPECTIVE
}

\author{
Wei-Lun CHANG ${ }^{1}$, Chia-Ling CHIU ${ }^{2}$ \\ ${ }^{1,2}$ Tamkang University, No.151, Yingzhuan Rd., Tamsui Dist., New Taipei City, Taiwan \\ E-mails: ${ }^{1}$ wlc.allen@gmail.com (corresponding author); ${ }^{2}$ itslynn412@gmail.com
}

Received 4 June 2015; accepted 19 April 2016

\begin{abstract}
Airline companies join airline alliances to cope with the high level of competition in the airline industry. However, pressure within an alliance is substantial. This study used competitor mapping and awareness-motivation-capability competitive dynamics to analyze airline alliances. The results revealed that alliances compete to recruit airline companies, and the power differences in the alliances are considerable; only a few of the airline companies within the alliance possess power. In addition, we interviewed 2 senior managers to confirm the results of the analysis. A detailed content analysis was performed to test each hypothesis. The findings revealed that companies with low market commonality and high resource similarity can cooperate through resource allocation. We also discovered that the main competitive action was derived from disallowing local airline companies to join an alliance. Leading companies in the alliance generally negotiated for the entire alliance indirectly. This research suggests that companies cooperate not only to control cost but also to increase service quality.
\end{abstract}

Keywords: coopeition, awareness-motivation-capability, competitive dynamics, competitive mapping, service alliance, strategic management.

JEL Classification: M21, M16, M31, C52, F2, L8.

\section{Introduction}

Owing to the globalization and the demand for seamless travel, airline companies can no longer satisfy customer demands by operating alone (Hannigan et al. 2015). Since the establishment of the Star Alliance in 1997, three airline alliances worldwide now carry more than $55 \%$ of air passengers and earn $77 \%$ of the profit in the airline market according to 2014 annual report of each alliance. Bilotkach (2005) indicated that high competitive pressure still exists, but numerous companies join alliances to reduce costs and gain a competitive advantage in the market.

A report by Aviation Week revealed that some airline companies joined across several alliances, and Qantas announced its cooperation with Emirates, which currently does not belong to any alliance. One third of airline companies are dissatisfied with the alliance to which they currently belong, suggesting that the traditional airline alliance may disap- 
pear in the future (Sreenivasan 2012). Previous studies demonstrated that communication within existing alliances is typically limited to code sharing, segment booking, and the connection of positioning systems (LaRoche et al. 2012; Ratliff, Weatherford 2013).

Today, 53 of the top 100 airline companies are members of an alliance, with the exception of low-cost carriers. The recruitment rate of alliances in the airline industry is more than $70 \%$. Airlines from Middle Eastern countries and low-cost carriers have recently joined the alliance. Even independent airline companies and low-cost carriers still need to reconsider joining alliance nowadays. The importance of selecting alliance or forming new alliance is critical for coopetition to obtain economic scale in airline alliance.

Past studies have examined the advantages of joining an alliance, the selection of a financial indicator, and the selection of an alliance from a psychological perspective (Palia et al. 2008; Tsantoulis, Palmer 2008). Most studies have used the awareness-motivation-capability to analyze competitive performance (Fraher 2013), pricing decisions (Isler, Imhof 2008; Yang, Campus 2011; Collins, Thomas 2013), and entry response (Selove 2014).

Particularly, some problems still remain in the airline industry, such as airline companies are struggling with alliance, competition is more than cooperation among companies, customers are benefit oriented, and related costs are high in the industry. This research aims to investigate the competitive actions and reactions in the alliance and cross alliances. The current study will propose three research questions by incorporating dynamic competitive perspective:

RQ1: How airline companies select the appropriate airline alliance to join?

RQ2: How competitive actions influence other members and what reactions occur to respond in airline alliances?

RQ3: How airline alliances enhance coopetition and reduce disputes among members?

The theoretical contribution is to extend existing knowledge to new concept of service alliance and resource-based theory. The practical contribution is to analyze airline industry deeper with different perspective in strategic management. The present paper is organized as follows. In section 1, we review the literature on airline alliance and awareness-motivation-capability competitive dynamic analysis. Section 2 explains the theoretical foundations. Section 3 provides detailed case analysis. Section 4 provides the implications and final section is the key findings of conclusions.

\section{Literature review}

\subsection{Airline alliances}

In the late 1970s, U.S. airline companies developed new business models that involved cooperating with other companies to construct a networked organization (Gillen, Morrison 2005); these developments initiated the establishment of airline alliances (Pels et al. 2001). An airline alliance is an agreement between two or more companies to perform code sharing, and is also a strategic alliance. We defined airline alliance as two or more airline companies that collaboratively pursue a united goal based on individual 
benefits according to an agreement (Keller, Aaker 1992; Parkhe 1993; Yoshino, Rangan 1995). Expanding the market and profits to new countries depends on the support and assistance of airline alliances (Lazzarini 2007). Airline alliances provide additional aviation lines to help members efficiently deliver consistent services in the global market (Brueckner 2003).

Additionally, there are six types of airline alliance. The first type of alliance shares ground facilities and operations. Members of this type of alliance share and maintain ground facilities, check-in counters, and baggage claims to improve operating benefits. The second type of alliance is a code-sharing alliance, which is the most popular strategy in the airline industry. Several studies have investigated the benefits and advantages of code sharing and how to improve the efficiency of code sharing (Saglietto 2009; Albers 2010). The third type of alliance involves a collaborative shipping agreement among members that guarantees certain amount of cargo and provides discounts during a specific time period. This type of agreement is beneficial to all members, particularly airline companies with stable customers.

The fourth type of alliance involves the coordination of flight schedules. The members develop an integrated platform for coordinating flight schedules, and the goal is to complement each other and acquire new customers. The fifth type of alliance entails the joint development of technology. The sixth type of alliance involves joint marketing, promotion, and advertising. After joining this type of alliance, the alliance becomes a new brand for the members. This study will examine competitive action and emphasized the value of service in determining the holistic value of airline alliances.

\subsection{Awareness-motivation-capability (AMC) competitive dynamic analysis}

Competition is a relative action. Companies adjust the position in the market to obtain a competitive advantage by using competitive actions and responses (Chen 1996). The theory of competitive dynamics is applied in analyzing the two sides of competition and discussing competitive actions and responses (Chen 2008). Analysis of competitive actions and reactions is useful for determining the competitive relationship between a specific company and its competitors in a market. Chandler (1962) indicated a strategy involves combining means and ends and using a company's resources to gain the most competitive position and create a competitive advantage. Numerous researchers have discussed competition theory (Porter, Millar 1985; Hamel 1998; Drucker 2007). Since the twentieth century, the dynamic environment of the airline industry has been complex and unpredictable. Bain (1950) and Porter (1980) conducted competitive dynamic analyses that emphasized competitors as well as understanding the series of actions and responses of competitors.

By interacting with competitors, companies may encounter more competition or collaboration. Barney (1991) identified two critical theories regarding strategy based on based on Penrose (1959): (a) the resource-based theory and (b) the dynamic competitive theory. The AMC model emphasizes the interaction of enterprises and complements the concepts of industry structure presented by Porter and Millar (1985) and strategic grouping. Mishra (2013) used AMC competitive dynamic theory to analyze U.S. manufactur- 
ers and demonstrated that competition can be imitated to improve industry development. Ghertman and Guedri (2012) demonstrated that the AMC model can enable companies to manage the entire competition process and enhance competition. This study aims to use AMC competitive dynamic theory to analyze historical data of airline alliances, including actions of all airline companies. The research goal is to understand past and current strategies; furthermore, connecting to future movement in airline industry.

\section{Methodology}

\subsection{Research framework}

In this study, we categorized three airline alliances based on market and resources to generate competitor mapping (Chen 1996) and analyze competitors' reactions. In addition, we discuss the possibility of service alliances in the airline industry. Compared with statistical analysis, the proposed framework more closely approximates reality (Fig. 1).

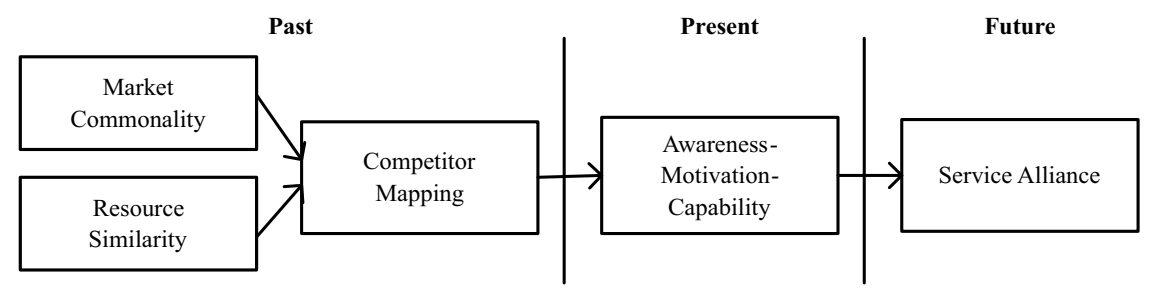

Fig. 1. Research framework (Adapted from Chen 1996)

\subsection{Theoretical foundation}

\subsubsection{Awareness-motivation-capability dynamic competition}

AMC dynamic competition theory is used to analyze the behaviors and reactions among competing companies in a specific market. The framework enfolds four analyses (Fig. 2): (a) competitor analysis, (b) analysis of the factors of competitive action, (c) analysis of competitive action and reactions, and (d) outcomes analysis.

Three drivers are also used: awareness, motivation, and capability. The first driver is awareness, which is the precondition of any competitive actions, reactions from a company, or reactions from competitors. Awareness is the perception of a competitor's actions and recognition of the relationship with the resistance-initiating company. When a company perceives that a competitor engages in competitive action, the possibility of preparing and executing a reaction plan is high. The second driver is motivation, which is the basis on which companies execute resistive actions. The action most likely to

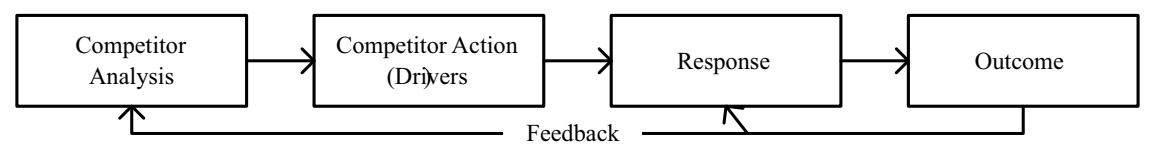

Fig. 2. Awareness-motivation-capability competitive dynamic framework (Source: Chen 1996) 
motivate resistance from competitors is attacking competitors' core market. The third driver is capability, which supports the overall resistive power of a company and is related to resource coordination and the decision-making process. Capability determines the type and intensity of responses, timing, and speed of resistance. The possibility of resistance is low if the technological threshold is high, resource allocation is high, or the competitor is unsure how to respond.

\subsubsection{Competitor mapping}

Competitor mapping is a method used to rigidly define a company's position in the market based on two constructs: market commonality and resource similarity. The first construct is market commonality, which represents the degree of market overlap between a company and other competitors within an alliance. A high degree of market commonality for a specific airline company obviously and directly identifies as a competitor. The second construct is resource similarity, which determines how a company reacts to aggression. A high degree of resource similarity indicates companies can cooperate to create an economy of scale.

We used a relative ratio ( $50 \%$ as the middle) to separate the $\mathrm{x}$ axis and $\mathrm{y}$ axis on a generated map to form four quadrants. According to the resource-based theory, the most suitable partner with which to form an alliance is a company with highly overlapping technological resources. The resource configuration of a strategic alliance is considered horizontal resource configuration We used the measure developed by Chen (1996) to modify the original definition based on our needs by defining market commonality as the degree of market overlap between competitors and focus companies. The mathematical model is expressed as follows:

$$
M_{a b}=\sum_{i=1}^{n}\left[\left(\frac{P_{a i}}{P_{a}}\right) *\left(\frac{P_{b i}}{P_{i}}\right)\right],
$$

where $M_{a b}$. represents the market commonality between competitor $\mathrm{b}$ and focus company a; $P_{a i}$. is the number of passengers of company a on route $\mathrm{i} ; P_{a}$. is the total number of passengers of company a on all routes; $P_{b i}$. is the total number of passengers of company $\mathrm{b}$ on all routes; and $P_{i}$. is the total number of passengers of all airline companies on route i. We defined resource similarity as the endowment of resources of a specific competitor to compete with the focus company. The mathematical model is expressed as follows:

$$
D_{a b}=\sum_{i=1}^{n}\left[\left(\frac{P_{a m}}{P_{a}}\right) *\left(\frac{P_{b m}}{P_{i}}\right)\right],
$$

where $D_{a b}$ is the market similarity between company $\mathrm{b}$ and focus company a; $P_{a m}$ is the number of airplanes used by company a for service $\mathrm{m} ; P_{a}$ is the total number of airplanes used by company a; $P_{b m}$ is the number of airplanes used by company $\mathrm{b}$ for service $m ; P_{i}$ is the total number of airplanes of all airline companies providing service $\mathrm{m}$; and $m$ is the service that both companies a and $\mathrm{b}$ provide. 


\subsubsection{Service alliances}

The idea of service alliance is based on service-dominant logic and service blueprint. Based on a study of Lovelock (1999), we divided airline service into several detailed services, including flight attendant service, kitchen service, and cargo service. According to the concept of service blueprint, services may be divided into processes and diagnosed for the possibility of cooperation. Value co-creation is also important among companies by sharing or exchanging resources. Heterogeneity creates service exchange with no standard and reduces the benefits of service exchange (Weber 2005). This study used alliances as the basis for proposing a novel concept called "service alliance". Service alliance is an alliance that enables companies to share and exchange services. We used a matrix to present various options for actions and enable the formulation of inferences regarding the optimal action (Table 1). In order to simplify the idea of service alliance, this research only uses three airline companies for elaboration: A, B, and C. In the matrix, 1 represents a service provided by a company and 0 represents a service outsourced to members of the alliance.

Table 1. Service alliance matrix for the airline industry

\begin{tabular}{|c|c|c|c|c|c|}
\hline & & \multirow{2}{*}{\multicolumn{4}{|c|}{$\mathrm{C}$}} \\
\hline & & & & & \\
\hline & & \multicolumn{2}{|c|}{1} & \multicolumn{2}{|c|}{0} \\
\hline & & \multicolumn{4}{|c|}{ B } \\
\hline & & 1 & 0 & 1 & 0 \\
\hline \multirow[t]{2}{*}{ A } & 1 & $(1,1,1)$ & $(1,0,1)$ & $(1,1,0)$ & $(1,0,0)$ \\
\hline & 0 & $(0,1,1)$ & $(0,0,1)$ & $(0,1,0)$ & $(0,0,0)$ \\
\hline
\end{tabular}

In an airline alliance, each company has a distinct strategy and outcomes vary according to competitors' strategies (Osborne 1994). The matrix clearly shows possible actions within the service alliance. Members of the service alliance base decisions on available resources. We analyzed the future of service alliances by using the AMC framework.

\section{Data analysis}

\subsection{Case study research and content analysis}

Case study research is a logic method for connected research question and context with multiple evidences (Platt 1992). This research is the exploratory and explaining case study to discover what, how, and why questions of observed phenomenon. We investigated why airline companies apply to a specific alliance, what types of competitive actions are performed within the alliance, and how airline companies respond to these actions. In this research, we mixed exploratory and interpretive hybrid embedded cases. The term "embedded case" refers to a case study involving multiple subunits of analysis (Reddy 2015).

According to the IATA end-year report in 2014, the spend on air transport increased $4.8 \%$ compared to 2013 . The transport cost decreased 55\% compared to 1994 . Fuel 
use increased 3\%, but the fuel efficiency decreased 3\% compared to 2013. Labor costs increased $4.8 \%$ compared to 2013 . The net post-tax profit of all areas around the world increased over year; particularly, 5.5\% in North America. The information revealed the industry slightly progressed but the labor and cargo costs still have rooms to improve.

In this research, the background was the airline industry, the sub-background was the three airline alliances, and the embedded units of analysis were the airline companies in each alliance. We referenced news, academic studies, and reports from third parties such as the Centre for Aviation (CAPA), Airline Daily, and Airline Business. We also conducted open and focus interviews (Merton et al. 1990) to obtain information from the senior managers of two airline companies in March 2014 (China Airlines and EVA Air). The validation of multiple sources is based on principles of methodological triangulation (Patton 1990).

To analyze 12 airline companies, we used a four-step structured content analysis. First, we used official information from airline alliances, the CAPA, Daily Airline, and Airline Business to filter relevant information on 12 airline companies between January 2011 and December 2013, and to distinguish types of competitive actions (Smith et al. 1992). Second, we separated the data into two categories: strategic and tactical. Strategic competitive action represents changes outside of industrial regulations. Tactical action refers to commitment to fixed assets, and has little long-term influence. According to Chen (2008), market expansion, service and equipment improvement, vertical integration, mergers, downsizing, and strategic alliances are considered strategic actions, and price adjustments, changes in production lines, removal of existing routes, and establishment of terminals are considered tactical actions. Third, we analyzed the relevant data. Finally, we integrated the comments of experts during interviews and reached a consensus by performing data triangulation. This research covered 64 competitive actions and reactions, and 20 were randomly selected to be samples.

\subsection{Analysis of competitor mapping}

This study involved measuring market commonality and resource similarity to analyze leading airline companies in three alliances maintained throughout America, Europe, and Asia. Figure 3, Figure 4, Figure 5, and Table 2 indicate the results of competitor mapping for three airlines based on the calculation of collected data. In order to provide detailed elaboration, we selected the examples of U.S. airlines.

Table 2. Analysis of competitor mapping of airline alliances

\begin{tabular}{cccccc}
\hline Alliance & Location of headquarter & $\begin{array}{c}\text { Leading Airline } \\
\text { Company }\end{array}$ & Code & Competitors & $\begin{array}{c}\text { Appropriateness } \\
\text { for cooperation }\end{array}$ \\
\hline Star Alliance & Frankfurt, Germany & United Airline & UA & DL, AA & \\
\hline Skyteam & Amsterdam, Netherland & Delta Airline & DL & AA, UA & LH, BA, CA, CZ \\
\hline Oneworld & New York, USA & $\begin{array}{c}\text { American } \\
\text { Airline }\end{array}$ & AA & UA & \\
\hline
\end{tabular}




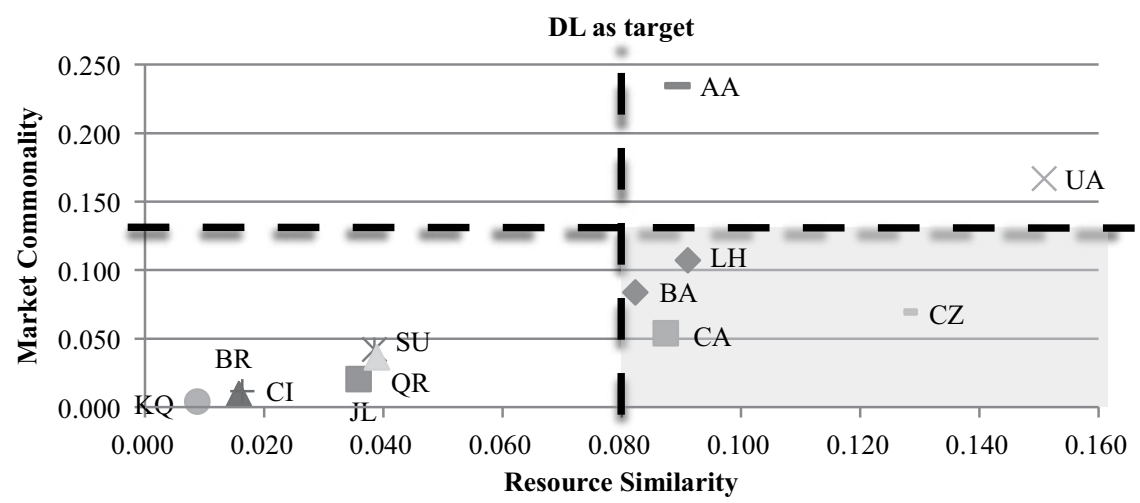

Fig. 3. Competitor mapping (Delta Air Lines as the target) (Source: the present research)

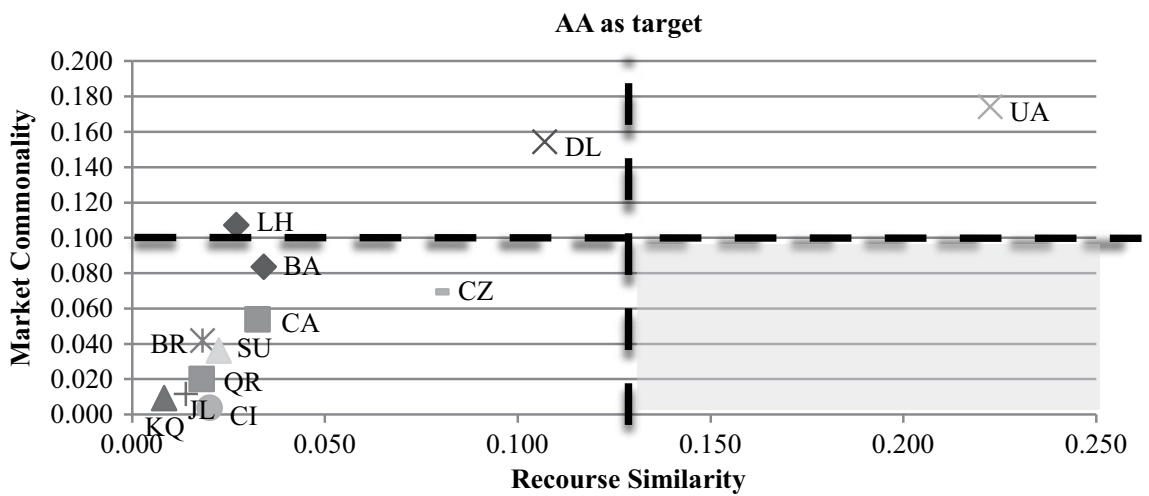

Fig. 4. Competitor Mapping (American Airlines as the target) (Source: the present research)

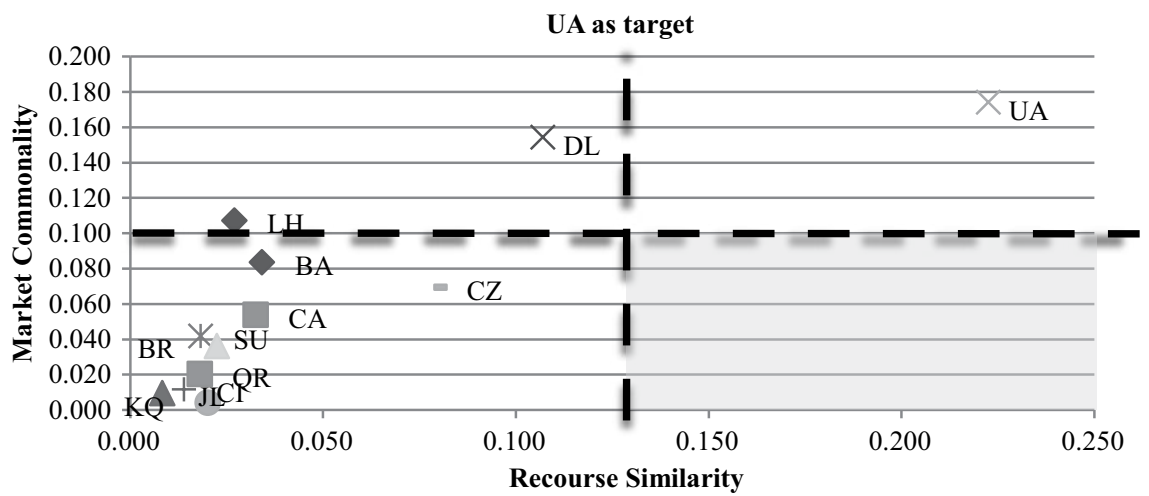

Fig. 5. Competitor Mapping (United Airlines as the target) (Source: the present research)

According to the competitor mappings, only DL cooperated with China Southern Airlines (CZ). DL and American Airlines (AA) were identified as the major competitors of United Airlines (UA). DL and AA both identified UA as a major competitor. DL and AA did not identify each other as major competitors. According to the interview with Senior 
Manager A, the reason that DL and AA do not compete is for the long-term protection of the U.S. airline industry. The core value of the U.S. airline industry is service. Senior Manager B stated that U.S. airline companies ask the government to create policies that benefit customers and raise the threshold for competitors to enter the U.S. market.

\subsection{Awareness-motivation-capability competitive dynamic analysis}

This study used the leading company of each alliance as the unit of analysis; specifically, UA represented Star Alliance, DL represented SkyTeam, and AA represented Oneworld. This study used events such as the increase in fuel prices in 2011, competition in the Asian airline market in 2012, and competition in the Indian airline market in 2012 to analyze the awareness, motivation, and capability of airline companies.

\subsubsection{Analysis of the increased fuel prices between August 2011 and June 2013}

The price of fuel has increased since 2011 because of the nuclear weapon crisis in Iran, the war in Libya, and the explosion in the Federal Republic of Nigeria. The first airline to react to the increase in fuel price was DL, and the effects of the event lasted 668 days. The improvement of equipment or integration of internal and external processes is considered invisible action with low competitive awareness. We observed that low awareness and competitive action resulted in a low response. Regarding motivation, the behaviors of the initiator of airline company were downsizing and increasing fuel use tax. Competitors were highly motivated to resist (or respond). Regarding capability, the first priority was to downsize and increase prices; these tactics require a low technological threshold. The second priority was to merge and integrate internal processes; these tactics require a high technological threshold. The increase in fuel prices particularly influenced the airline industry. The quick responses of airlines to these events reveal the magnitude of fuel price increases and the effects of increases in fuel prices on the airline industry.

\subsubsection{Analysis of competitive action in the Asian market between June 2012 and June 2014}

Three airline companies became competitive when UA announced its transpacific partnership strategy, which was to shift its target market to major cities in Asia. The initiator was UA, and DL was the first airline to respond, responding 52 days after the announcement. UA used most of its efforts and resources in the Asia market. AA and DL then responded after three fiscal quarters, but UA had established stable operation in major cities in the Asian market. When UA began to focus on minor cities in the Asian market, AA expanded to major cities. This event indicates that DL and AA have strong awareness and capability. However, they both determined that responding too early may result in stronger competition and a lose-lose situation. The two senior managers interviewed both indicated that the profit gained from a route between Asia and the United States is similar to that gained from three to four domestic routes in the United States. Competition in the Asian market is a valuable opportunity and a challenge. UA competed in the Chinese market for 7 years. DL and AA realized that the market was mature and did not actively resist. The lack of motivation of DL and AA was caused by high awareness of competition and incompatibility. 


\subsubsection{Analysis of the competitive action of airline alliances between 2011 and 2014}

We assumed that airline alliances cooperate to avoid regulations and engage in code sharing. The collected data on alliances was mostly related to airlines joining or withdrawing from an alliance. However, implicit strategies and operation directions exist for leading companies in the United States. For instance, Japan Airlines (JL) experienced a financial crisis in 2009. DL offered 1 billion U.S. dollars to help JL and to pay the fine for withdrawing from the alliance. The leading company in Oneworld, AA, immediately offered 1.4 billion U.S. dollars to help JL, and criticized DL for "inappropriate action". JL then publicly thanked AA on February 19, 2010 and remained a member of Oneworld, cooperating more tightly than before. The largest scale of competition for the three alliances between 2011 and 2014 was the acquisition of the Indian market. However, Kingfisher Airlines, Jet Airways, and Air India were rejected because of financial problems.

The initiator of this event was Oneworld, and Sky Team and Star Alliance responded after 19 and 23 days, respectively. Competitive action was slow because of financial problems. We determined the main reason for slow competitive action to be a lack of competitive motivation. Competing in the Indian market may damage existing operations and benefits. Competitive action continued until December 2012, when three Indian airline companies merged. Sky Team was the first alliance to act, but exhibited low awareness, motivation, and capability. Generally, the time from application to approval is 2 years and companies must pay the cost before joining the alliance (Borekci et al. 2014). Airline companies must compete with other members of the alliance after joining the alliance. The senior managers that we interviewed both agreed with our interpretation of the data.

\subsection{Analysis of service alliances}

We propose a new concept called the service alliance, which is a model of potential future airline alliances. This research formulated a static game theory model and synthesized four strategies (Table 3).

Table 3. Service alliance concept

\begin{tabular}{ccccc}
\hline \multicolumn{1}{c}{ Type } & \multicolumn{4}{c}{ Non-cooperation static game theory } \\
\hline Participant & \multicolumn{4}{c}{ A, B, C in the alliance } \\
\hline Action & \multicolumn{3}{c}{ Self-Served } & \multicolumn{2}{c}{ Outsourcing } \\
\hline \multirow{2}{*}{ Strategy } & Outsource: 3 & Outsource: 2 & Outsource: 1 & Outsource: 0 \\
& Self-served: 0 & Self-served: 1 & Self-served:2 & Self-served:3 \\
\hline
\end{tabular}

\subsubsection{All self-served strategy}

Crew service is used to illustrate this strategy. The core of the airline industry is crew service, which involves having own airplane and pilots. The core value of crew service is security and reliability in accordance with quality and standard service. However, numerous companies outsource crew service to other members of their alliance or provide wet leases to other airline companies. This strategy may create confusion for customers 
and conflicts between airline companies. For example, Malaysia Airlines flight MH370, which was also associated with China Southern, was lost on March 8, 2014. Although people considered Malaysia Airlines responsible for the flight, suspects to be onboard the flight purchased their tickets from China Southern according to the report from CNN in March 2014 ${ }^{1}$. Security is always the critical concern in the airline industry. Outsourcing crew service for cost concerns may create problems for airline companies.

\subsubsection{Two self-served services and one outsourced service strategy}

Flight attendant service is used to illustrate this strategy. Flight attendant service is the most crucial service onboard an airplane because flight attendants engage in direct contact with customers. In 2012, Skytrax recognized Malaysia Airlines as providing the best service in the world and KLM as providing the best service in Europe. Both Malaysia Airlines and KLM are members of Oneworld. However, no airline companies outsource flight attendant service, mainly because of service heterogeneity, cultural differences, and differing company visions. In a service alliance, leading companies with advanced or similar services can help other companies in the alliance.

\subsubsection{One self-served service and two outsourced service strategies}

Catering service, which is the most popular outsourced service in the airline industry, is used to illustrate this strategy. Numerous airline companies select catering services from non-allied members. In a service alliance, companies with superior catering services can form an independent company and provide catering services to other members. This strategy can ensure service quality and consistency as well as enable companies to obtain an economy of scale and cost advantages. Competition among catering services would increase based on the benchmarks. Thus, the entire value of the alliance would be enhanced, attracting additional airline companies.

\subsubsection{A team in the alliance that provides a specific service}

Cargo service is used to illustrate this strategy. Cargo service has a low entrance threshold and emphasizes cost benefits on an economic scale. Sky Team has created a cargo alliance called Skyteam Cargo, which has become the largest cargo service in the airline industry and was awarded the title of best cargo service in 2005. Several new members joined the alliance to receive the benefits of this cargo service. The advantage of a cargo alliance is shared terminals. Providing seamless and consistent quality can reduce route construction costs and attract superior airline companies.

\subsection{Findings}

In this study, we identified competing companies that exhibit high market commonality and resource similarity as well as asymmetry. Standing by our analysis and findings, we endeavor to develop an integrated theoretical framework of airline alliances rooted in the AMC and competitive dynamics. We also suggest some propositions to further our understanding and in need of future research (Fig. 6).

\footnotetext{
${ }^{1}$ http://edition.cnn.com/2014/03/08/world/asia/malaysia-airlines-plane-missing/
} 
Research Question

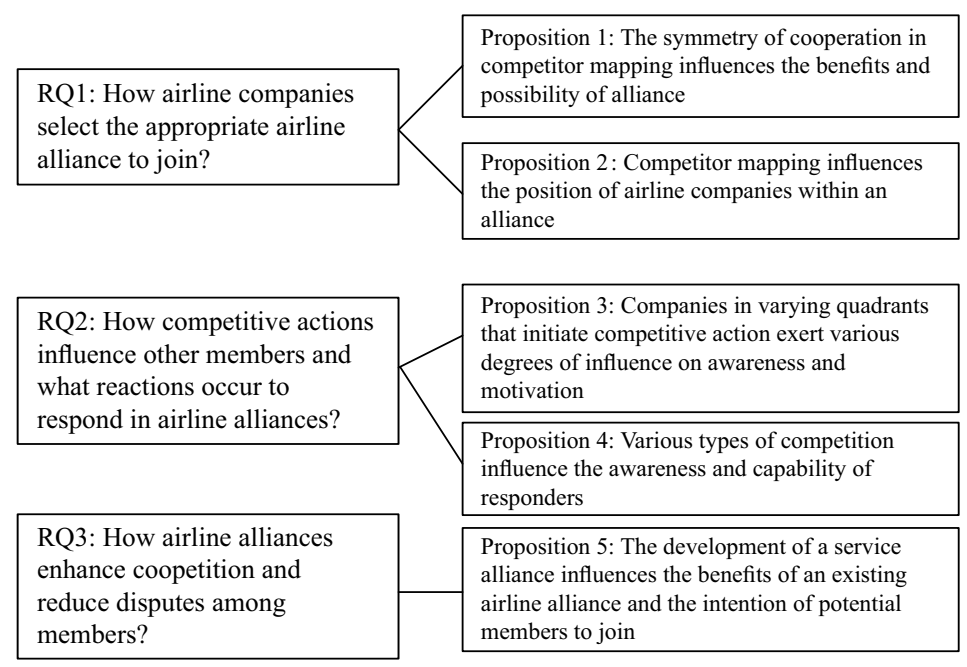

Fig. 6. Framework and proposition

Proposition 1: The symmetry of cooperation in competitor mapping influences the benefits and possibility of alliance.

According to the concept of asymmetrical competition (Chen 2008), no asymmetric relationship exists even identified competitors. We considered cooperation to be a complementary relationship. Existing explanations merely focus on competition and lack of coopetition. Therefore, companies must identify each other by using competitor mapping to determine the possibility of forming an alliance.

Proposition 2: Competitor mapping influences the position of airline companies within an alliance.

Competitor mapping can help existing or potential members in an alliance discover new positions. Without paying a fine for withdrawing from an alliance, airline companies can select other companies featuring high resource similarity and low market commonality with which to cooperate. Therefore, competitor mapping not only affects the loyalty of members of an alliance but also affects the intention of potential members to join an alliance.

Proposition 3: Companies in varying quadrants that initiate competitive action exert various degrees of influence on awareness and motivation.

Companies that exhibit high market commonality and resource similarity are considered major competitors and cannot cooperate. If these companies do not respond or respond slowly to main attackers, then they experience substantial losses. Therefore, companies must pay close attention to the actions of identified competitors and respond quickly.

Proposition 4: Various types of competition influence the awareness and capability of responders. 
The determined companies perform strategic actions such as price adjustments, production line changes, and creation of new routes; these actions require speed, high awareness and capability, and few resources. Competitors may respond to tactical actions by performing similar actions. Response time is short, and the goal is to attain balance between actions and responses. Strategic actions, particularly those executed in middle- to long-term strategies, require additional preparation time. The goal of these actions is to coordinate resources, and responders generally react carefully to strategic actions. Numerous companies first respond using tactical actions, and then resist using strategic actions.

Proposition 5: The development of a service alliance influences the benefits of an existing airline alliance and the intention of potential members to join.

We proposed the concept of the service alliance to remove the obstacles of existing alliances based on a customer-centered mindset. Service alliances cooperate in various manners to improve existing benefits and attract potential members. Increasing the tightness of cooperation increases the benefits of an alliance.

\section{Implications}

\subsection{Discover opportunity of coopetion under alliance}

This research combined competitor mapping and AMC competitive dynamics to analyze airline companies. AMC competitive dynamics enables companies to understand competitors' responses and actions within an alliance. Airline companies may discover the opportunity of cooperation based on competition. Airline alliances may discover the possibility of competition based on cooperation. This research provides different perspectives that reflect various strategic movement to airline company or airline alliance.

\subsection{Position competitor efficiently in the industry}

Our research supplements resource-based view by positioning in the market. Airline companies can understand competitors in advance and put effort on limited resources to react. Competitor mapping also has measurement flexibility and time flexibility. Airline industry is extremely competitive owing to high similarity of companies. Our concept and findings provide new perspective to understand status quo of dynamic environment. Companies may utilize resource-based view to look deeper and wider with different viewpoint.

\subsection{Apply service alliance to current airline industry}

Several alliances attempted to recruit low-cost airline companies (Lerrthaitrakul, Panjakajornsak 2014); however, the profit in the airline industry quickly declines. We propose the concept of the service alliance as a new opportunity for airline alliances. The concept of service alliance is to help airline companies reduce service costs by cooperation and enhance competitive advantage. Distinguished services can represent high quality, creating value and satisfying customer needs (Chang 2014). The improvement of service quality will attract more opportunities of cooperation inside airline alliance and become more competitive outside airline alliance. 


\section{Conclusions}

In this study, we used competitor mapping to analyze the market commonality and resource similarity of airline companies based on public reports and statements. The results revealed that companies with low market commonality and high resource similarity can cooperate through resource allocation. Cooperation among companies with high market commonality and high resource similarity is not appropriate $(R Q 1)$. Potential members obtain the greatest benefits by joining alliances with numerous members, high market commonality, and low resource similarity. Joining an alliance with too many members, high market commonality, and high resource similarity may not be beneficial.

The results also revealed the main competitive action was derived from disallowing local airline companies to join an alliance. Leading companies in the alliance generally negotiated for the entire alliance indirectly. We used leading companies as the unit of analysis because of the unequal power within the alliance. Companies with high resource similarity and low market commonality initiated competitive action exhibited strong awareness and motivation. Tactical actions received responses indicating high awareness and capability, and the frequency of response was high (RQ2).

Moreover, we propose a novel concept of service alliance to identify excellent service providers within an alliance. Superior companies may outsource services to increase the benefits of the alliance and focus on customer perceived value. Exchanging or supporting services enables companies to provide on-demand services to customers. In addition, we suggest that companies cooperate not only to control cost concerns but also to increase service quality $(R Q 3)$.

This study also had several limitations. First, we used only leading companies in alliances because our data sources were limited. Second, we generated a competitor map based on data collected between 2011 and 2014 and an annual report from 2013. The dynamic nature of the airline industry may engender frequent changes in data. Third, the concept of service alliance is novel and needs more verification. Our propositions may not apply to existing low-cost airlines which are essentially cost-oriented not serviceoriented. However, our concept can apply to compare purely low-cost airlines with same basis. In summary, more examples can be provided to enable its application to the airline industry.

\section{References}

Albers, S. 2010. Configurations of alliance governance systems, Schmalenbach Business Review 62(3): 204-233.

Bain, J. S. 1950. Workable competition in oligopoly: theoretical considerations and some empirical evidence, The American Economic Review 40(2): 35-47.

Barney, J. B. 1991. Firm resources and sustained competitive advantage, Journal of Management 17(1): 99-120. http://dx.doi.org/10.1177/014920639101700108

Bilotkach, V. 2005. Price competition between international airline alliances, Journal of Transport Economics and Policy 39(2): 167-189.

Borekci, D.; Rofcanin, Y.; Sahin, M. 2014. Effects of organizational culture and organizational resilience over subcontractor riskiness: a multi-method study in longitudinal time setting, European Business Review 26(1): 2-22. http://dx.doi.org/10.1108/EBR-07-2013-0099 
Brueckner, J. K. 2003. International airfares in the age of alliances: the effects of code sharing and antitrust immunity, Review of Economics and Statistics 85(1): 105-118.

http://dx.doi.org/10.1162/003465303762687749

Chandler, A. D. 1962. Strategy and structure. MA: MIT press Cambridge.

Chang, W. L. 2014. Service mining framework and application. NY: Business Expert Press.

Chen, M. 1996. Competitor analysis and interfirm rivalry: toward a theoretical integration, Academy of Management Review 21(1): 100-134.

Chen, M. J. 2008. Reconceptualizing the competition-cooperation relationship: a transparadox perspective, Journal of Management Inquiry 17(4): 288-304.

http://dx.doi.org/10.1177/1056492607312577

Collins, A. J.; Thomas, L. 2013. Learning competitive dynamic airline pricing under different customer models, Journal of Revenue \& Pricing Management 12(5): 416-430.

http://dx.doi.org/10.1057/rpm.2013.10

Drucker, P. F. 2007. Management challenges for the twenty-first century. Routledge.

Fraher, A. L. 2013. Airline downsizing and its impact on team performance, Team Performance Management 19(1/2): 109-126. http://dx.doi.org/10.1108/13527591311312123

Ghertman, M.; Guedri, Z. 2012. Rivalry and forbearance in the European airline industry: evidence of an inverted U-shaped competitive pattern, Management international/International Management/Gestiòn Internacional 16(4): 23-40.

Gillen, D.; Morrison, W. G. 2005. Regulation, competition and network evolution in aviation, Journal of Air Transport Management 11(3): 161-174.

http://dx.doi.org/10.1016/j.jairtraman.2005.03.002

Hamel, G. 1998. Alliance advantage: the art of creating value through partnering. Harvard Business Press.

Isler, K.; Imhof, H. 2008. A game theoretic model for airline revenue management and competitive pricing, Journal of Revenue \& Pricing Management 7(4): 384-396.

http://dx.doi.org/10.1057/rpm.2008.30

Keller, K. L.; Aaker, D. A. 1992. The effects of sequential introduction of brand extensions, Journal of Marketing Research 29(1): 35-50. http://dx.doi.org/10.2307/3172491

Hannigan, T. J.; Hamilton III, R. D.; Mudambi, R. 2015. Competition and competitiveness in the US airline industry, Competitiveness Review25(2): 155-134.

http://dx.doi.org/10.1108/CR-11-2014-0036

LaRoche, M.; Gamache, M.; Olivier-Ouellet, J. 2012. Optimization of codeshare flight selection for an airline company, INFOR: Information Systems and Operational Research 50(1): 31-39. http://dx.doi.org/10.3138/infor.50.1.031

Lazzarini, S. G. 2007. The impact of membership in competing alliance constellations: evidence on the operational performance of global airlines, Strategic Management Journal 28(4): 345-367. http://dx.doi.org/10.1002/smj.587

Lerrthaitrakul, W.; Panjakajornsak, V. 2014. The airline service quality affecting post purchase behavioral intention: empirical evidence from the low cost airline industry, International Journal of Trade, Economics and Finance 5(2): 155-158.

Lovelock, C. H. 1999. Developing marketing strategies for transnational service operations, Journal of Services Marketing 13(4/5): 278-295. http://dx.doi.org/10.1108/08876049910282538

Merton, R. K.; Fiske, M.; Kendall, P. L. 1990. The focused interview: a manual of problems and procedures. London: Collier McMillan.

Mishra, R. 2013. The competitive dynamics of a firm's capacity position and inventory leanness activities: evidence from us manufacturing industries [online], [cited 18 April 2016]. Available from Internet: http://dspace.uta.edu/handle/10106/23909 
Osborne, M. J. 1994. A course in game theory Cambridge. MIT Press.

Palia, D.; Ravid, S. A.; Reisel, N. 2008. Choosing to cofinance: analysis of project-specific alliances in the movie industry, Review of Financial Studies 21(2): 483-511.

http://dx.doi.org/10.1093/rfs/hhm064

Patton, M. 1990. Qualitative evaluation and research methods. Beverly Hills, CA: Sage.

Parkhe, A. 1993. Strategic alliance structuring: a game theoretic and transaction cost examination of interfirm cooperation, Academy of Management Journal 36(4): 794-829.

http://dx.doi.org/10.2307/256759

Pels, E.; Nijkamp, P.; Rietveld, P. 2001. Airport and airline choice in a multiple airport region: an empirical analysis for the San Francisco bay area, Regional Studies 35(1): 1-9.

http://dx.doi.org/10.1080/00343400120025637

Penrose, E. T. 1959. The theory of the growth of the firm. New York: Sharpe.

Platt, J. 1992. Case study in American methodological thought, Current Sociology 40(1): 17-48. http://dx.doi.org/10.1177/001139292040001004

Porter, M. E. 1980. Industry structure and competitive strategy: keys to profitability, Financial Analysts Journal 36(4): 30-41. http://dx.doi.org/10.2469/faj.v36.n4.30

Ratliff, R.; Weatherford, L. R. 2013. Codeshare and alliance revenue management best practices: AGIFORS roundtable review, Journal of Revenue and Pricing Management 12(1): 26-35.

http://dx.doi.org/10.1057/rpm.2012.23

Reddy, K. S. 2015. Beating the Odds! Build theory from emerging markets phenomenon and the emergence of case study research - a "test-tube" typology, Cogent Business \& Management 2(1): $1-25$.

Saglietto, L. 2009. Airline alliances: when competitiveness can be approached with specific social networks, Competitiveness Review: an International Business Journal Incorporating Journal of Global Competitiveness 19(4): 304-322. http://dx.doi.org/10.1108/10595420910977425

Selove, M. 2014. A dynamic model of competitive entry response, Marketing Science 33(3): 353-363. http://dx.doi.org/10.1287/mksc.2013.0827

Smith, K. G.; Grimm, C. M.; Gannon, M. J. 1992. Dynamics of competitive strategy. Sage Publications, Inc.

Sreenivasan, V. 2012. Bye bye, airline alliances? Changing relationships shaking up cosy clubs, The Business Times, 11 October 2012 [online], [cited 18 April 2016]. Available from Internet http://search.proquest.com/docview/1095696013?accountid=14237

Tsantoulis, M.; Palmer, A. 2008. Quality convergence in airline co-brand alliances, Managing Service Quality 18(1): 34-64. http://dx.doi.org/10.1108/09604520810842830

Weber, K. 2005. Travelers' perceptions of airline alliance benefits and performance, Journal of Travel Research 43(3): 257-265. http://dx.doi.org/10.1177/0047287504272029

Yang, X.; Campus, N. K. 2011. Competitive network and competitive action: a study of the US airline industry, Academy of Strategic Management Journal 10(1): 45-63.

Yoshino, M. M. Y.; Rangan, U. S. 1995. Strategic alliances: an entrepreneurial approach to globalization. Harvard Business Press.

Wei-Lun CHANG is Professor of Department of Business Administration in Tamkang University (Taiwan). His research interests are related to service analytics, sentiment analysis on social networks, and topics in IS field. His publications have appeared in Information Systems Frontiers, Service Business, Telematics and Informatics, Communications of the ACM, Knowledge-Based Systems, Journal of Information Science, etc.

Chia-Ling CHIU is teaching assistant of Department of Business Administration in Tamkang University (Taiwan). She received her MBA from Department of Business Administration of Tamkang University. She has published papers in international conference suc as AMCIS, AOM, and AMS. 